Абдюшева Д.Р.

аспирант, ФГБОУ ВО

«Государственный Университет

Управления», г. Москва

e-mail: d.abdyusheva@gmail.com

Меренков А.O.

канд. экон. наук, ФГБОУ ВО

«Государственный университет

управления», г. Москва

e-mail: artem-merenkov@yandex.ru

\section{Степанов А.A.}

д-р экон. наук, ФГБОУ ВПО «Государственный университет управления», г. Москва

e-mail: astepanov@guu.ru

\section{Abdyusheva D.R}

Graduate student, State University of Management, Moscow

e-mail: d.abdyusheva@gmail.com

\section{Merenkov A.0.}

Candidate of Economic Sciences, State University of Management, Moscow

e-mail: artem-merenkov@yandex.ru

\section{Stepanov A.A.}

Doctor of Economic Sciences, State University of Management, Moscow

e-mail: astepanov@guu.ru

\section{Условия построения маркетинговой системы «цифрового» транспорта и логистики в управлении
конкурентоспособностью}

\section{Аннотация}

В последнее время вновь актуальным становится вопрос развития систем автоматизации на транспорте. Заметим, что первые разработки в сфере автоматизированных систем управления датируются серединой XX века, когда в СССР развивалась кибернетика. Со временем элементь автоматизации получили развитие в авиации, автомобильном и железнодорожном транспорте. Однако уровень развития научно-технического прогресса позволил лишь спустя долгие годы вернуться к этому вопросу на качественно новом уровне. Очередной этап развития технологий предполагает развитие элементов искусственного интеллекта (цифровизацию) во многих отраслях реального сектора экономики. Эволюция информационных технологий позволила компаниям притворять в жизнь концепцию маркетингового (клиентоориентированного подхода). В настоящее время учет мнения потребителей, обеспечение сервиса качественно иного уровня-первый фрактор обеспечения конкурентоспособности компании, выгодно подчеркивающий ее положение на рынке. Целью исследования является изучение условий формирования системы цифрового транспорта и логистики. Задачами, определившими ход научных разработок, являлись: определение основных принципов, характерных для цифрровой экономики в транспортно-экспедиционном и логистическом обслуживании, выявление основных задач и условий формирования системы цифрового транспорта и логистики. В результате исследований конкретизированы основные условия цифровизации транспорта и логистики, обозначены необходимые, определены достаточные условия функционирования данной системы с учетом территориальных особенностей России. Выявлены основные преимущества развития цифрового транспорта для участников перевозочного процесса. Подчеркнута роль современных технологий в процессе реализации принципов клиентоориентированного подхода на транспорте, что способствует повышению качества работы компаний сферы транспортно-экспедиционного и логистического обслуживания.

\section{Ключевые слова:}

цифровой транспорт и логистика, цифрровая экономика, клиентоориентированный подход, цифрровой сервис, провайдер услуг, транспортно-территориальный каркас.

\section{Conditions of construction of the system of digital transport and logistics in the management of competitiveness}

\begin{abstract}
Recently, the issue of the development of automation systems in transport is again becoming topical. Note that the first developments in the field of automated control systems (ACS) date back to the mid-20th century, when cybernetics was developing in the USSR. Over time, automation elements have developed in aviation, road and rail transport. However, the level of development of scientific and technological progress allowed only after many years to return to this issue at a qualitatively new level. The next stage in the development of technologies involves the development of elements of artificial intelligence (digitalization) in many branches of the real sector of the economy. The evolution of information technologies allowed companies to put into practice the concept of a marketing (customer-oriented approach). At present, taking into account the opinion of consumers, providing a service of a qualitatively different level, the first factor of ensuring the competitiveness of the company, advantageously emphasizing its position in the market. The purpose of the study is to study the conditions for the formation of the system "digital» transport and logistics. The tasks that determined the course of scientific developments were: to determine the basic principles that are characteristic of the «digital economy» in freight forwarding and logistic services, to identify the main tasks and conditions for the formation of a system of «digital» transport and logistics. "As the research results, the following provisions should be singled out: the authors specify the basic conditions for the digitization of transport and logistics, identify the necessary conditions, and determine the sufficient conditions for the functioning of this system, taking into account the territorial features of Russia. The authors revealed the main advantages of digital transport development for the participants of the transportation process. The article highlights the role of modern technologies in the process of implementing the principles of a client-oriented approach to transport, which contributes to the improvement of the quality of work of companies in the sphere of freight forwarding and logistics services.
\end{abstract}

\section{Keywords:}

digital transport and logistics, digital economy, client-oriented approach, digital service, service provider, transport-territorial carcass.

(C) The Author(s), 2018 This is an open access article under the CC BY 4.0 license (http://creativecommons.org/licenses/by/4.0/) 
Сегодня государственная политика преуспевающих стран мира направлена на развитие цифровой экономики в отраслях реального сектора экономики. «Цифровая экономика - это не отдельная отрасль, по сути, это основа, которая позволяет создавать качественно новые модели бизнеса, торговли, логистики, производства, изменяет формат образования, здравоохранения, госуправления, коммуникаций между людьми, а, следовательно, задает новую парадигму развития государства, экономики и всего общества» [3].

Цифровизация транспорта и логистики, как одной из социальных отраслей, использование современных технических средств, программ, позволяет повысить эффективность функционирования транспортного комплекса, обеспечить высокое качество услуг.

В настоящее время термин «цифровая экономика» понимают как фреймовую экономику готовых, заданных решений, быстро адаптирующихся к потребностям пользователя. Отличительной чертой цифровой экономики также является необходимость соединения «больших данных» (big data) с экономико-значимыми потребностями клиентов, а также использование в работе интерфейсов (язык общения с клиентом), пригодных для восприятия неспециалистами, расширения сегментов потенциальной клиентуры. Понятие потребности является ключевым в цифровой экономике. И важнейшая задача - цифровизация потребностей на основе CRM-систем (англ. customer relationship management или управление отношениями с клиентами), которые становятся частью процесса создания цифрового клиентского сервиса [1].

Цифровая трансформация реального сектора экономики - междисциплинарная и комплексная задача. Вызов такого рода связан с появлением ряда возможностей (рис. 1).

Необходимым условием формирования системы «цифрового» транспорта и логистики является реализация клиентоориентированного механизма развития экономических систем, на основе цифрового взаимодействия, ценностных потоков данных, необходимых для получения сетевого эффекта при решении оперативных и стратегических задач государства, бизнеса и населения [5].

«Цифровой» транспорт и логистика должны состоять из нескольких уровней. Необходимым условием работы данной системы является развитие техникотехнологической основы, охватывающей транспортные средства, технические устройства, линейные коммуникации, автоматизацию ряда операций.

Другой важной задачей системы является обеспечение клиентского сервиса цифрового уровня. При

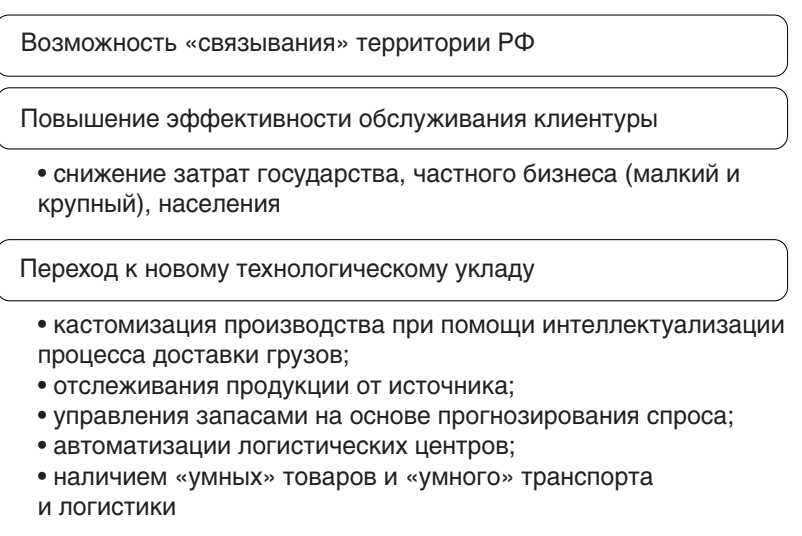

Развитие элементов экономики “совместного пользования» при построении цифровой логистической системы

Участие в международной кооперации
• цифровые транспортные коридоры
Развитие клиентоориентированного подхода
• аутсорсинговая система;
• система самообслуживания
Свободный обмен данными
• электронный документооборот;
в стимулирование стандартов развития агентов по обмену
данными
Совершенствование нормативно-правовой базы

- таможенное регулирование;

- отраслевые стандарты;

- законодательство в части обмена информации;

- стандарты в части внедрения Инфрормационных технологий

Источник: [1]

Рис. 1. Основные задачи цифровой логистики В транспортном комплексе России

этом под цифровым сервисом понимаются условия, при которых клиенту получает индивидуальное качество услуг по ценам массового производства (характерная черта открытой экономики), т. е. персонификация продуктов и транспортно-логистических сервисов в условиях массового производства. Развитие цифрового сервиса также будет способствовать активизации взаимодействия между платформами, развитие которых является условием формирования системы цифрового транспорта и логистики.

Исследуя клиентский уровень заметим, что процесс взаимодействия технико-технологических элементов должен органически вписываться в существующую экосистему пользователей, помогать им с точки зрения удовлетворения насущных потребностей клиента [1]. Наличие разнообразных контрольных устройств, связанных единой глобальной информационной сетью, будет использоваться в системе 
цифрового транспорта и логистики и приведет к значительным изменениям в доставке.

Некоторыми задачами такого взаимодействия являются:

- автоматизация отдельных операций (погрузка, разгрузка, упаковка груза, взвешивание, выдача груза и т. д.);

- автоматизация бизнес-процессов (складирование, ездка);

- взаимодействие машин между собой;

- сбор, обработка данных;

- обеспечение информационного сервиса;

- кооперация с прикладными программными продуктами;

- машинное обучение и т. п.

Авторитетная компания McKinsey в своем докладе «Цифровая Россия: новая реальность» констатирует, что РФ уже сегодня живет в цифровой эпохе. Симптомами подобной трансформации являются: количество пользователей интернета (первое место в Европе), доля пользователей смартфонов (60 \% граждан), количество пользователей порталов государственных услуг (40 млн чел.) [7]. Это создает у пользователей предпосылки к формированию «привычки к цифре», когда человек ощущает себя комфортно в условиях электронной среды.

В этих условиях задача оператора транспортнологистического рынка сводится к выбору заданного алгоритма действия из библиотеки стандартизированных решений. При этом возможность оперировать решениями создается благодаря цифровизации логистических цепочек (в зависимости от типа грузы, вида транспорта), их адаптации к параметрам клиентской подсистемы. Это позволит не только изучить поведение клиента в прошлом, но и построить точную модель-прогноз возможных потребностей в будущем. Потребности могут трансформировать способы потребления до совместного использования и сокращать необходимые ресурсы (carshering).

Исследуя клиентскую систему заметим, что обозначенное выше повышение цифрового сервиса также будет заключаться в необходимости упрощения пользовательского доступа к услугам, визуализации потребностей пользователя, его обучение, оказании клиентской поддержки в режиме 24/7, развитии мобильных клиентских сервисов, переходу от модели фиксированной услуги к «услуге по требованию», повышению качества пользовательского интерфейса систем. Это объясняется тем, что экономически активным становится новая формация пользователей, сформировавшаяся в условиях «цифровой» эпохи [2].
В свою очередь задача создания достаточных условий эффективного функционирования «цифрового» транспорта и логистики состоит в создании для пользователей необходимых условий, возможностей обеспечения взаимодействия между клиентом и оператором логистических услуг. Подобная работа строится на основе взаимодействии платформ, опирающихся на существующий транспортно-территориальный каркас, а также учитывающих топографические особенности конкретной местности, региона.

Типологизация платформ носит следующий характер.

1. В зависимости от территории различают:

- международный уровень (межгосударственный);

- государственный;

- уровень региона;

- субъектный уровень;

- местный уровень.

2. По виду транспорта:

- автомобильный;

- железнодорожный;

- внутренний водный;

- морской;

- воздушный.

3. По видам обслуживания:

- международные транспортные компании;

- транспортные компании федерального уровня;

- региональный транспорт;

- индивидуальные предприниматели.

Платформизация системы «цифрового» транспорта и логистики потребует обеспечения ряда условий организационного, правового, социального характера.

Как показало исследование зарубежного опыта в сфере построения «цифрового» транспорта и логистики, процесс создания данной структуры на транспорте сводится к созданию национальных центров развития. Концепция основывается на концентрации имеющихся знаний, опыта, технологий и компетенций на основе тесного взаимодействия государства, частного сектора, населения. В частности, высока роль государства в регулировании взаимодействия экономических субъектов, создание условий «цифрового доверия» [8]. Мнение общественности также необходимо, ведь с автоматизацией ряда операций многократно превышается производительность труда, возникают явления безработицы даже среди специалистов высокой квалификации. В этой связи остро стоит задача подготовки нового уровня управленцев-инженеров.

Другими рисками цифровой экономики будут являться: 
- маргинализм;

- изменение роли государства, необходимость обеспечения «цифрового суверенитета» страны;

- усиление глобальной, цифровой конкуренции в различных секторах экономики;

- необходимость обеспечения кибербезопасности (защита персональных данных, кибертерроризм, обеспечение надежности денежных переводов и т. д.); - необходимость пересмотра законодательства;

- занятость (безработицы, «черная» занятость) [6]. Для развития «цифрового» транспорта необходимо, чтобы поставленные задачи и решения базировались не только на имеющимся опыте, но и учитывали современные тенденции, опиратясь на национальные особенности транспортной системы.

Так, протяженность железных дорог в России за последние четверть века сократилась на 2,5 тыс. км (в основном за счет закрытия ряда малодеятельных линий) [8; 9]. На сегодняшний день семь субъектов РФ до сих пор не имеют железных дорог, в десяти субъектах железнодорожная сеть слабо развита (рис. 2).

Приблизительно 2/3 страны до сих пор являются малоосвоенной территорией, к тому же имеют неблагоприятный климат для проживания населения, однако именно на таких территориях находятся месторождения полезных ископаемых, что в перспективе удовлетворило бы экономические интересы государства.

В основу реализации тенденции развития транспортного комплекса России необходимо учесть следующие принципы.

1. Сохранение стратегических (геополитических и геоэкономических) интересов России во взаимо- отношениях с соседними государствами, а именно поддержание транспортной инфраструктуры.

2. При строительстве новых магистралей на малоосвоенных территориях в перспективе должно произойти увеличение плотности дорожной сети РФ.

3. Очертание территориального пространства РФ и конфигурация сети уже построенных (эксплуатируемых) на этом пространстве путей диктует стратегическую необходимость приоритетного строительства новых линий большой протяженности, прежде всего, в широтном направлении (Восток Запад), которые следует проложить севернее Транссиба и БАМа. На западе и северо-западе европейской части России эти линии должны иметь выходы в существующие и будущие (новые) порты Балтийского, Баренцева и Белого морей. На Дальнем Востоке и северо-востоке РФ широтные железнодорожные магистрали должны иметь выходы в порты Японского, Охотского и Берингова морей.

4. Выбирая принципиальное направление будущих широтных коридоров, следует по возможности обеспечить достаточное число связей их с существующими линиями, что наряду с увеличением взаимодействия железных дорог, повысит маневренность сети в малоосвоенных регионах России.

5. Последующее расширение транспортной сети должно осуществляться посредством строительства инфраструктуры местного значения, которые обеспечат местному населению круглогодичную возможность транспортной доступности в любой регион РФ. К числу линий местного значения следует отнести и такие, которые создают необходимые условия для эффективной разработки новых месторождений полезных ископаемых.

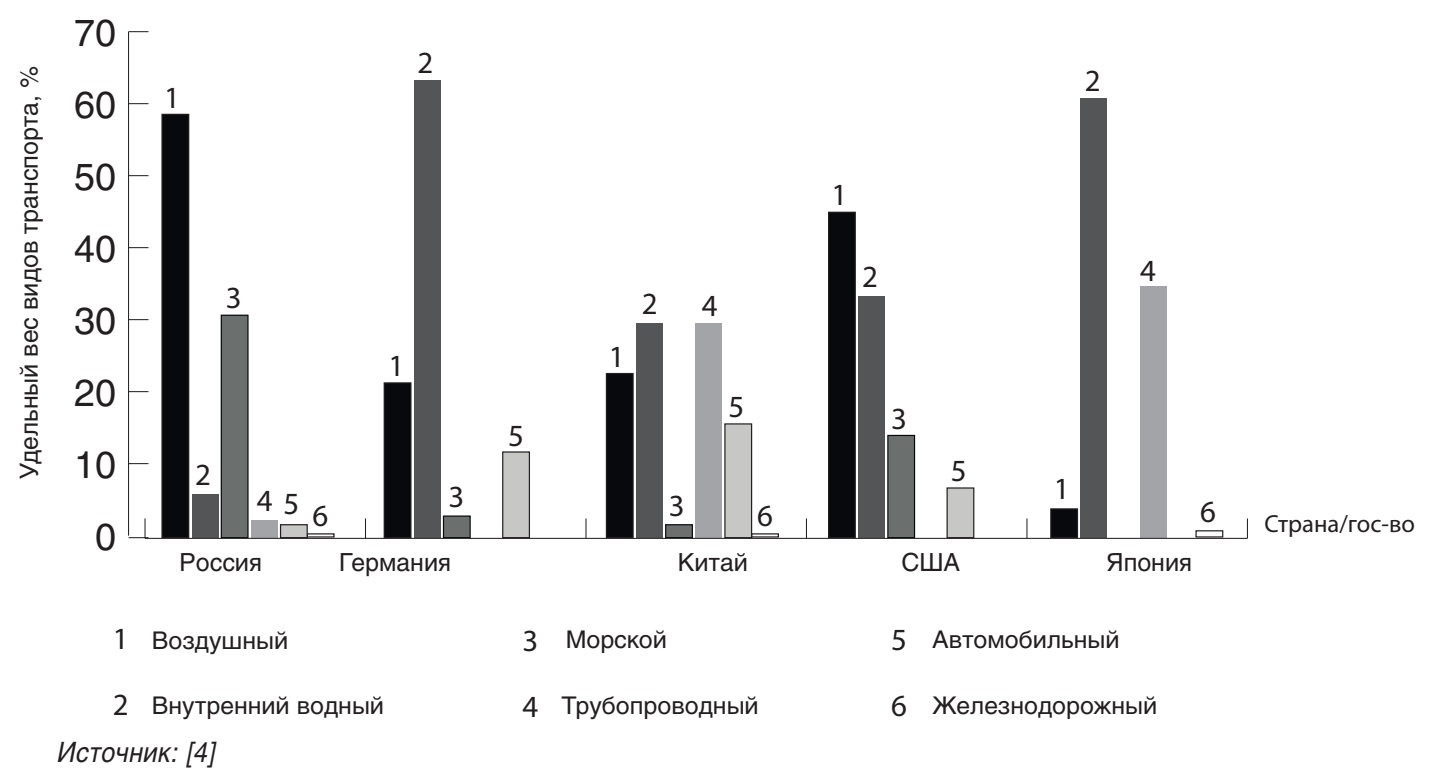

Рис. 2. Удельный вес отдельных видов транспорта в общем грузообороте (без газопроводного) в 2008 г., \% 
Преимущества «цифровой логистики» для участников перевозочного процесса

\begin{tabular}{|c|c|}
\hline Участники перевозочного процесса & Преимущества \\
\hline Грузоотправители/грузополучатели & $\begin{array}{l}\text { 1. Возможность получения услуг по перевозке грузов по более выгодным условиям. } \\
\text { 2. Сокращение затрат на поиск более выгодных операторов. } \\
\text { 3. Снижение фактора коррупции. } \\
\text { 4. Понимание рыночной ситуации и прогнозирование }\end{array}$ \\
\hline Перевозчики & Создание цивилизованной и открытой системы продаж услуг железнодорожного транспорта \\
\hline Операторы & $\begin{array}{l}\text { Создание новых механизмов реализации охвата потенциальных клиентов. } \\
\text { Улучшение собственной деятельности за счет профессионализма, повышения квалификации } \\
\text { рабочих }\end{array}$ \\
\hline $\begin{array}{l}\text { Владельцы путей необщего } \\
\text { пользования }\end{array}$ & Создание нового механизма реализации собственных услуг \\
\hline Регуляторы & $\begin{array}{l}\text { Появление рычагов влияния на рынок грузовых перевозок, прозрачность перевозок, недопуще- } \\
\text { ние создания монополизации рыночных позиций приводящему к спекулятивному повышению цен }\end{array}$ \\
\hline
\end{tabular}

Составлено авторами по материалам исследования

6. Необходимость в строительстве любой новой транспортной инфраструктуры может быть признана рациональной лишь в том случае, если с вводом ее в эксплуатацию создаются благоприятные условия для развития хозяйственной деятельности в районе ее тяготения, что откроет дополнительные возможности для повышения экономической активности населения.

7. Строительство новой и модернизация действующей транспортной инфраструктуры Российской Федерации составляет общую стратегическую программу комплексного развития Единой транспортной системы страны, учитывающую необходимость развития всех видов транспорта [7].

Таким образом, формирование «цифрового» транспорта и логистики должно опираться на существующий транспортно-территориальный каркас, а также учитывать топографические особенности конкретной местности (топографический фактор). Развитие территорий напрямую связано с развитием транспортной сети. Стратегическое решение транспортных проблем по-видимому направлено на реализацию единой политики в области транспорта, градостроительства и землепользования, что представляет собой обязательным условием для достижения высокого уровня транспортного обслуживания, повышения степени использования городских территорий, улучшения качества жизни населения (табл. 1).

Таким образом, развитие «цифрового» транспорта и логистики будет залогом повышения экономической активности не только в федеральных центpax, но и в малых городах, находящихся на пересечении различных платформ. Это благоприятно скажется на экономики всей страны. «Цифровой» транспорт и логистика будут способствовать повышению скорости циркуляции экономики, повышению уровня клиентского сервиса, качества жизни населения страны, снижению транспортной компоненты в структуре товаров и услуг, производимых народным хозяйством страны. Это потребует учета необходимых социальных и технических факторов, внесения правок в законодательство, а также изменений организационного характера.

\section{Библиографический список}

1. Абдюшева, Д. Р. Условия построения системы «цифрового» транспорта и логистики / Д. Р. Абдюшева, А. А. Степанов, А. О. Меренков // Шаг в будущее: искусственный интеллект и цифровая экономика: материалы 1-й Международной научно-практической

\section{References}

1. Abdyusheva D. R Usloviya postroeniya sistemy` «cifrovogo» transporta i logistiki [Conditions for constructing a system of «digital» transport and logistics] / D. R. Abdyusheva, A. A Stepanov, A. O. Merenkov // Step into the Future: Artificial Intelligence and Digital Economy: materials of the 
конференции. Вып. 1 / Государственный университет управления. - М.: Издательский дом ГУУ, 2017. C. 6-10.

2. Персианов, В. А. Информатизация управления и автоматизированного решения проектно-плановых задач на транспорта: монография / В. А. Персианов, А. В. Курбатова, А. Г. Липатов. - М.: Общество с ограниченной ответственностью «ТРАНСЛИТ», 2017. C. 176 .

3. Путин, В. В.: Внедрить цифровые технологии во все сферы жизни [Электронный ресурс]. - Режим доступа: https://rg.ru/2017/06/04/reg-szfo/vladimir-putin-vnedritcifrovye-tehnologii-vo-vse-sfery-zhizni.html (дата обращения: 13.06.2018).

4. Степанов, А. А. Концептуальные основы транспортноэкспедиционного и логистического обслуживания бизнеса и населения / А. А. Степанов, В. С. Горин // Вестник Университета. - 2011. - № 26. - С. 282-288.

5. Три базовых вещи цифровой экономики [Электронный pecypc]. - Режим доступа: https://www.itweek.ru/gover/ article/detail.php?ID=195253 (дата обращения: 13.06.2018).

6. Цифровая экономика [Электронный ресурс]. - Режим доступа: http://ac.gov.ru/files/content/11704/cifrovayaekonomika-pushkin-v-1-6-dlya-mozgovogo-shturma-pdf. pdf (дата обращения: 13.06.2018).

7. Железная дорога 4.0 [Электронный ресурс]. - Режим доступа: http://www.pult.gudok.ru/archive/detail. php?ID=1385465 (дата обращения: 13.06.2018).

8. WEF 2017 [Электронный ресурс]. - Режим доступа: https://www.weforum.org/agenda/2017/01/designingiinnovation-policies-in-emerging-economies (дата обращения: 13.06.2018). 1st International Scientific and Practical Conference.State University of Management. Moscow: Publishing House SUM, 2017, pp. 6-10.

2. Persianov V. A., Kurbatova A. V., Lipatov A. G. Informatizaciya upravleniya i avtomatizirovannogo resheniya proektno-planovy'x zadach na transporta: monografiya [Informatization of management and automated solution of project-planning tasks for transport: monograph]. Moscow: Limited Liability Company «TRANSLIT», 2017, pp. 176.

3. Stepanov A. A., Gorin V. S. Konceptual`ny`e osnovy` transportno-e kspedicionnogo i logisticheskogo obsluzhivaniya biznesa i naseleniya [Conceptual foundations of forwarding and logistics services for business and the population] // Bulletin of the University, 2011, I. 26, pp. 282-288.

4. Cifrovaya ehkonomika [Digital economy]. Available at: http://ac.gov.ru/files/content/11704/cifrovayaekonomika-pushkin-v-1-6-dlya-mozgovogo-shturma-pdf. pdf (accessed 13.06.2018).

5. Tri bazovy`x veshhi cifrovoj e'konomiki [Three basic things of the digital economy]. Available at: https://www.itweek.ru/ gover/article/detail.php?ID=195253 (accessed 13.06.2018).

6. Zheleznaya doroga 4.0 [The railway 4.0]. Available at: http://www.pult.gudok.ru/archive/detail.php?ID=1385465 (accessed 13.06.2018).

7. Putin V.V.: Vnedrit cifrovy`e texnologii vo vse sfery`zhizni [Vladimir Putin: To introduce digital technologies in all spheres of life]. Available at: https://rg.ru/2017/06/04/reg-szfo/ vladimir-putin-vnedrit-cifrovye-tehnologii-vo-vse-sferyzhizni.html (accessed 13.06.2018).

8. WEF 2017. Available at: https://www.weforum.org/ agenda/2017/01/designing-iinnovation-policies-inemerging-economies (accessed 13.06.2018). 